\title{
Nurmikkoalueiden perustamisessa ja hoidossa energiaa kuluu monessa eri vaiheessa.
}

\author{
Oiva Niemeläinen ${ }^{1}$ ja Frans Silvenius ${ }^{2}$ \\ ${ }^{1}$ MTT Kasvintuotanto, MTT Planta, 31600 Jokioinen, oiva.niemelainen@mtt.fi \\ ${ }^{2}$ MTT Biotekniikka ja elintarviketutkimus, Latokartanonkaari 9, 00790 Helsinki, frans.silvenius@mtt.fi
}

Tiivistelmä

"LCA in landscaping” -hankkeessa kehitetään elinkaarianalyysiä sovellettavaksi nurmikon perustamiseen ja hoitoon. Elinkaarianalyysin tulosten pohjalta voitaisiin perustettavat nurmikot suunnitella erilaiset ympäristövaikutukset mahdollisimman hyvin huomioon ottaviksi. Primäärienergian kulutuksen määrän arviointi on yksi keskeinen tehtävä analyysin tekemisessä. Hankkeessa tarkastellaan erityisesti kuinka kierrätysmateriaaleja hyödyntävien kasvualustojen ja/tai lannoitustuotteiden käyttö vaikuttaa viherrakentamisen primäärienergian tarpeeseen. Erilaisten kasvualustaratkaisujen lisäksi käytetään siemenseoksia joiden kasvuvoimakkuus ja siten leikkuutarve vaihtelevat. Projekti pyrkii lisäämään kiinnostusta ja mahdollisuuksia kierrätysmateriaalien hyödyntämiseen viherrakentamisessa ja elinkaarianalyysin käyttöä eri ratkaisujen ympäristövaikutuksia tarkasteltaessa. Hankkeessa esitellään kierrätysmateriaalien käyttöä nurmikkokohteissa eri paikkakunnilla Suomessa. Hankkeessa on tähän mennessä tuotettu pohjaa elinkaarimallinnukselle nurmikon leikkuun polttoaineenkulutuksista ja pienikokoisten nurmikkoalueiden perustamisesta. Hankkeesta on lisätietoja saatavissa verkkosivuilla: www.lcainlandscaping.fi.

Asiasanat: elinkaarimallinnus, energian kulutus, kasvualusta, LCA, niitto, nurmikko, puistot, viherrakennus. 


\section{Johdanto}

Elinkaaritarkastelu koskee koko tuotteen kaikkia ympäristövaikutuksia tuotteen koko elinkaaren alueelta tai joltain tietyltä osalta. Se on iteratiivinen prosessi: yksittäisissä tutkimuksen vaiheissa hyödynnetään muiden vaiheiden tuloksia. Läpinäkyvyys on keskeistä - raportoitava menetelmien kuvaus, oletukset ja rajaukset (ISO 2006). Hiilijalanjälki viittaa tuotteen tai palvelun koko tuotanto- (ja kulutus-) ketjun aikana syntyviin ympäristövaikutuksiin. Elinkaaritarkastelun soveltaminen mm. golfkenttien toimintaan on herättänyt kiinnostusta (Tarmio 2011) ja ensimmäisiä tarkasteluja elinkaarianalyysin soveltamisesta puistoalueiden perustamiseen ja hoitamiseen on tehty (Russo ja Grassi 2010).

Tavoitteena on tuottaa systeemimalliin perustuva verkkopohjainen elinkaaritarkasteluväline, jossa komponentteina ovat kasvualustan tuottaminen, nurmikon perustaminen ja nurmikon hoito. Nykyisin käytössä olevia ”perinteisiä” menettelyjä nurmikon perustamisessa ja hoidossa käytetään elinkaaritarkastelumallin lähtöaineistona. Tuotettava väline mahdollistaa erityyppisten viheralueiden perustamiseen ja hoitoon liittyvien vaihtoehtoisten ratkaisujen vertaamisen.

\section{Aineisto ja menetelmät}

Systeemimalli tarkastelee nurmikon tuottamisen seuraavissa komponenteissa: raaka-aineen hankintaan liittyvät prosessit, kasvualustan tuottaminen, perustamisvaiheen toimet ja nurmikon hoitamiseen liittyvät toimet.

Kasvualustan raaka-ainetuotantoon liittyvät toimet: kompostointi, mädättäminen, maansiirrot ja käsittelyt, turpeen prosessointi, jätemateriaalien työstämien käyttökelpoisiksi ovat ensimmäiset elinkaaritarkastelussa huomioon otettavat prosessit. Tarkastelu kattaa kaikki viheralueen perustamiseen ja hoitoon liittyvät toimet, joita ovat mm. maa-ainesten siirto, tasaus, muokkaus, nurmikon leikkuu, sadetus, lannoitus ja kalkitus. Tarkastelu lasketaan nurmikon eripituisille käyttöajoille. Käytettävien materiaalien ympäristövaikutukset otetaan huomioon ja kohdennetaan ao. vaiheeseen viheralueen tuotantoketjussa.

Elinkaaritarkastelumallia käytetään hankkeen esittelykohteiden suunnittelussa tuottamaan vaihtoehtoja, jotka eroavat ympäristövaikutuksiltaan toisistaan. Kaikki ympäristövaikutuksen pääluokat: primäärienergia, ilmastonmuutosvaikutus, rehevöityminen, ympäristömyrkkyvaikutukset ja happamoituminen sekä vesijalanjälki ovat mukana. Keskeisimmät ovat hiili- ja vesijalanjälki ja rehevöitymisvaikutus. Systeemimallia käytetään määrittelemään ympäristöindikaattorit kestävälle kasvualustan tuotannolle, nurmikon perustamiselle ja hoidolle. Elinkaaritarkastelun avulla voidaan määrittää keskeisten vaikuttavien tekijöiden kriittiset arvot varmistamaan kierrätysmateriaaleja hyödyntävien viherrakentamisratkaisujen ekologinen kestävyys.

Mallin jokainen pääkomponentti jaetaan yksikköprosesseiksi ja kunkin prosessin ympäristövaikutus arvioidaan. Päähuomion kohteena ovat suurimmat ympäristövaikutukset tuottavat prosessit sekä kierrätysmateriaalien käytön tuottamat vaikutukset.

Materiaalia energian kulutustarkasteluja varten tullaan keräämään kirjallisuudesta, alan ammattilaisten (viheralueiden hoitajat ja laitetoimittajat) haastatteluilla ja kyselyillä sekä tekemällä mittauksia polttoaineen kulutuksesta nurmikon perustamisen ja hoidon eri työvaiheissa ja kasvualustatuotannon prosesseissa sekä toisaalta myös nurmikkoalueiden hoitovaiheen typpioksiduuliemissioista sekä ravinnehuuhtoumista. Tietoja erityyppisten nurmikkojen niittotarpeesta saadaan hankkeen demonstraatiokentistä sekä astiakokeista. Ohessa kaaviokuva energiankäytön keskeisimmistä tarkastelukohdista nurmikon perustamisessa ja hoidossa. 


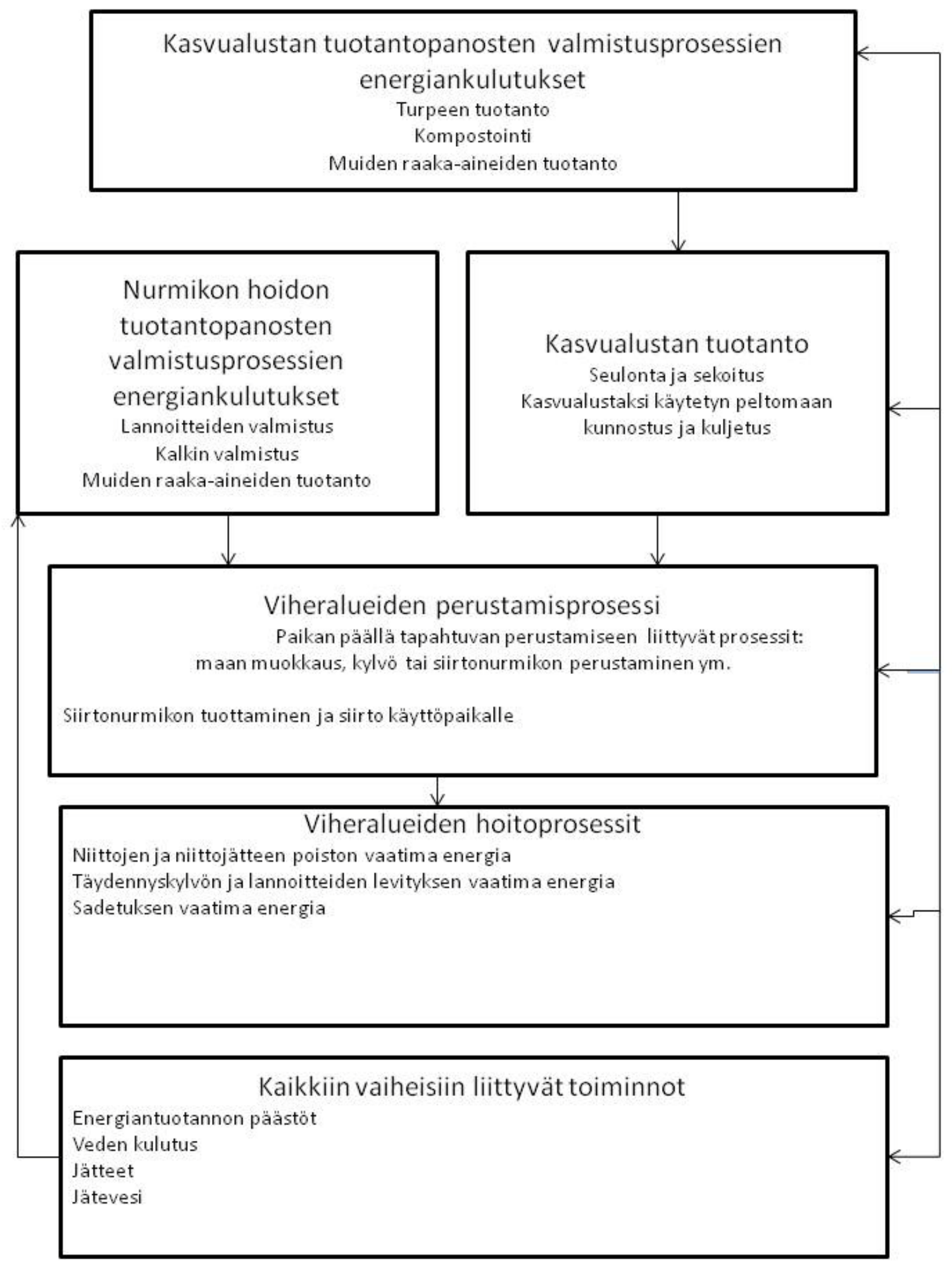

Kuva 1. Kaaviokuva primäärienergian käytön keskeisimmistä tarkastelukohdista nurmikkoalueiden perustamisen ja hoidon elinkaaritarkastelua tehtäessä. 
Hankkeessa perustettiin vuonna 2011 demonstraatiokenttiä Jokioisiin, Lepaalle, Poriin, Jyväskylään ja Hämeenlinnaan. Erityisesti Lepaan ja Jokioisten kenttä- ja astiakokeiden avulla pyritään tuottamaan lähtötietoja elinkaaritarkastelun lähtötietoja sellaisiin tietotarpeisiin, joista käyttökelpoisia tutkimustietoja tietoja ei ole saatavilla.

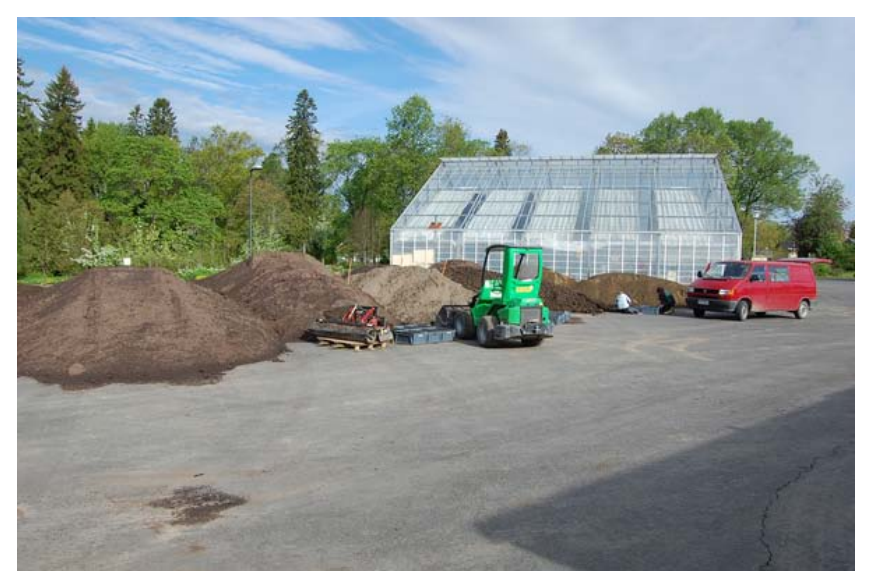

Kuva 2. Paikalla olevan maan poistaminen ja kasvualustan tuottaminen ja siirtäminen vaativat huomattavasti energiaa. Kyseessä on raskaiden massojen käsittelystä. Kuljetusmatkojen pituus on yksi tekijä. Kasvualustan kylvömuokkaus on myös energiaa vaativa toimenpide. Kuvassa kasvualustat Lepaalla toukokuussa 2011 odottamassa demokohteen perustamista. Kohteessa käytettiin Hämeenlinnan Seudun Veden, EnvorBiotechin ja Kekkilän kompostimultaa.

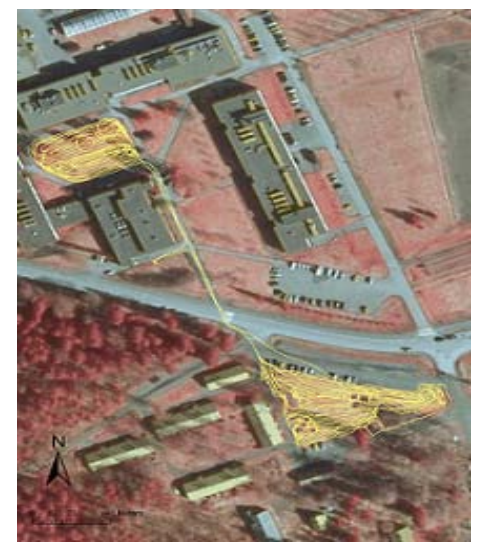

Kuva 3. Intensiivisessä hoidossa olevia nurmikkoalueita niitetään viikoittain kasvukauden aikana. Golf-kenttien viheriöitä niitetään lähes päivittäin. Puistonurmikoillakin niittokertoja voi tulla runsaat 20 kasvukaudessa. MTT:llä Jokioisissa kokeiltiin kesällä 2011 GPS-paikantimen käyttämistä nurmikon leikkuutyön dokumentoinnissa ja polttoaineen kulutuksen arvioinnissa.

\section{Tulokset ja tulosten tarkastelu}

Mallin käytössä tarvittava aineisto tuotetaan hankkeen kumppaneiden yhteistyöllä hyödyntämällä olemassa olevaa dataa ja hankkeessa toteutettavista demonstraatio- ja astiakokeista saatavia tietoja. Laskennan tuloksena määritellään ja testataan kahdeksasta kymmeneen kestävyyteen vaikuttavaa indikaattoria, joilla voidaan arvioida kierrätysmateriaaleja sisältävien tuotteiden vaikutusta nurmikon perustamisen ja hoidon hiili- ja vesijalanjälkeen. Aineiston keruu on alkanut ja perustamisvuoden tuloksia demonstraatiokentiltä on saatu. Aineistoa ei ole riittävästi tulosten esittämiseen. Tosin ensimmäisen vuoden kokemukset viittaavat, että sekä nurmikon kasvualusta että siemenseos vaikuttavat suuresti leikkuutarpeeseen. Todennäköisesti vaikutus tasoittuu suhteellisen pian ja ajan oloon vaikuttaa lannoitustarvetta vähentävästi. Elinkaaritarkastelumallin tuottaminen ja soveltaminen tulevat osoittamaan mistä prosesseista tarvitaan lisää tutkimustietoja. Muun muassa tarvitaan mittaustuloksia kasvihuonekaasujen vapautumisesta nurmikon 
perustamisvaiheessa. Mallin laskelmista saadaan myös osviittaa ovatko energian käytön osalta merkittävimpiä perustamisvaiheen toimet vai nurmikon leikkuusta aiheutuva energian kulutus.

\section{Johtopäätökset}

Tutkimustoiminta elinkaaritarkastelun soveltamiseksi viherrakentamiseen on viriämässä.

Elinkaaritarkastelumallin tuottaminen ja soveltaminen tulevat osoittamaan mistä prosesseista tarvitaan lisää tutkimustuloksia ja mihin prosesseihin keskittymällä voidaan saada suurimmat vaikutukset aikaan. Tämän hankkeen ensimmäiset laskelmat pyritään tuottamaan vuoden 2012 aikana.

\section{Kirjallisuus}

Fluck, R. C. and P. Busey. 1988. Energy for mowing turfgrass. Transactions of the American Society of Agricultural Engineers 31 (5): 1304-1308.

ISO (2006) Environmental managing. Life Cycle Assessment. Principles and framework. ISO 14040.

ISO (2006) Environmental managing. Life Cycle Assessment. Requirements and guidelines. ISO 14044.

Russo, G. ja A. Grassi. 2010. Environmental analysis of construction and management of urban parks by means of LCA. Proceedings of LCA food 2010 (Vol. 2) pp. 358-363.

Tarmio, T. 2011. Golfkenttä ja hiilijalanjälki. Suomen Golflehti 4/2011. pp: 50-57.
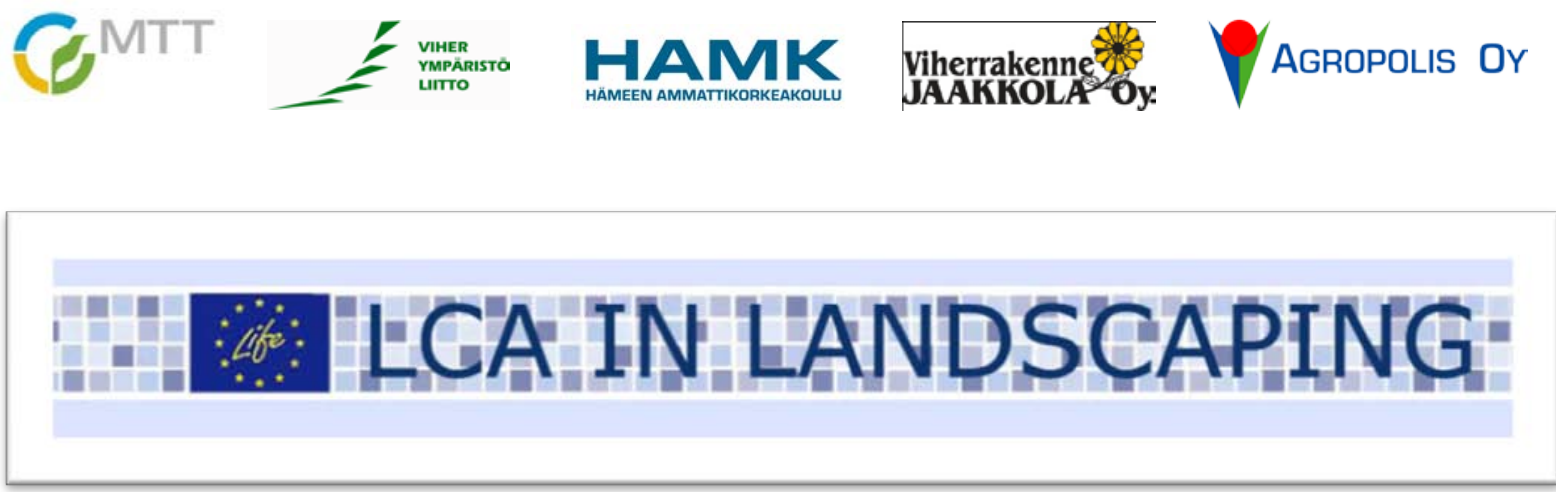